ARTICLE

\title{
Metal-free atom transfer radical polymerization with ppm catalyst loading under sunlight
}

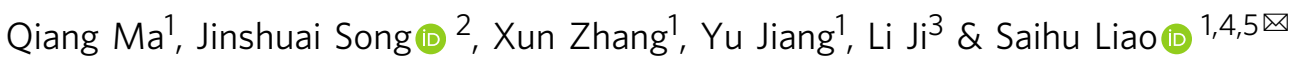

Organocatalytic atom transfer radical polymerization (O-ATRP) is recently emerging as an appealing method for the synthesis of metal-free polymer materials with well-defined microstructures and architectures. However, the development of highly effective catalysts that can be employed at a practical low loading are still a challenging task. Herein, we introduce a catalyst design logic based on heteroatom-doping of polycyclic arenes, which leads to the discovery of oxygen-doped anthanthrene (ODA) as highly effective organic photoredox catalysts for O-ATRP. In comparison with known organocatalysts, ODAs feature strong visible-light absorption together with high molar extinction coefficient $\left(\varepsilon_{455 \mathrm{~nm}}\right.$ up to $23,950 \mathrm{M}^{-1} \mathrm{~cm}^{-1}$ ), which allow for the establishment of a controlled polymerization under sunlight at low ppm levels of catalyst loading.

\footnotetext{
${ }^{1}$ Key Laboratory of Molecule Synthesis and Function Discovery (Fujian Province University), College of Chemistry, Fuzhou University, Fuzhou 350108, China. 
S ince the discovery in the 1990s, atom transfer radical polymerization (ATRP) has evolved into one of the most versatile and utilized polymerization methods for the synthesis of polymer materials with well-defined structures and architectures, and widely employed in a variety of industrial applications including coatings, adhesives, cosmetics, inkjet printings, etc. ${ }^{1-3}$ However, conventional ATRPs rely on transition metal catalysts [i.e., $\mathrm{Cu}(\mathrm{I}), \mathrm{Ru}(\mathrm{II})],{ }^{3}$ which will result in transition metal contaminations in the final products, and thus raise concerns when applied to fields sensitive to metal contaminants. ${ }^{4-6}$ Therefore, considerable efforts have been dedicated to lowering catalyst loadings or removing residual metals since the initial discovery of ATRP. ${ }^{5-8}$ Whereas, the recent emerging organocatalytic atom transfer radical polymerization (O-ATRP) using organic photoredox catalysts, undoubtedly, represents an ideal solution to this challenging issue. ${ }^{9-15}$

Since the conceptual work first demonstrated O-ATRP in 2014 by using organic molecules such as $N$-phenyl phenothiazine or perylene as a catalyst, ${ }^{16-18}$ it has immediately attracted wide research interests in the past 5 years. ${ }^{19-22}$ Until now, several frameworks/core structures ${ }^{22}$ including phenothiazine (1), $16,23,24$ dihydrophenazine (2), ${ }^{25-28}$ phenoxazine (3), ${ }^{29,30}$ etc. $^{31-37}$ have been successfully identified as efficient photocatalysts (PC) for $\mathrm{O}$ ATRP (Fig. 1a). However, a 1000-ppm level of catalyst loading was typically required to reach a satisfactory control over the polymerization. Controlled polymerization at a practical low catalyst loading $(<10 \mathrm{ppm})$ could not only eliminate the need of further product purification or residual catalyst removal, but

\section{a O-ATRP catalyst development via core structure modification (previous studies)}<smiles>c1ccc2c(c1)CNc1ccccc1S2</smiles>

phenothiazine<smiles>c1ccc2c(c1)Nc1ccccc1N2</smiles>

dihydrophenazine<smiles>c1ccc2c(c1)CNc1ccccc1O2</smiles>

phenoxazine core-modification<smiles>[X]c1c#[R]ccc1N([Al])c1ccccc1[R]</smiles>

$\mathrm{X}=\mathrm{S}(\mathbf{1}), \mathrm{NAr}(2), \mathrm{O}(\mathbf{3})$

\section{b O-ATRP catalyst design based on the heteroatom-doping logic (this work)}

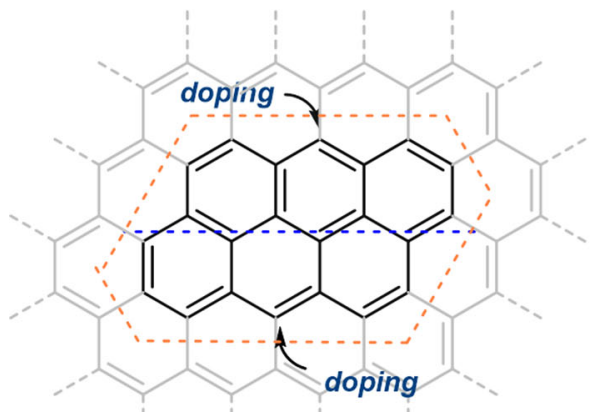

Anthanthrene

(extended $\pi$ system)

C Catalytic cycle for O-ATRP

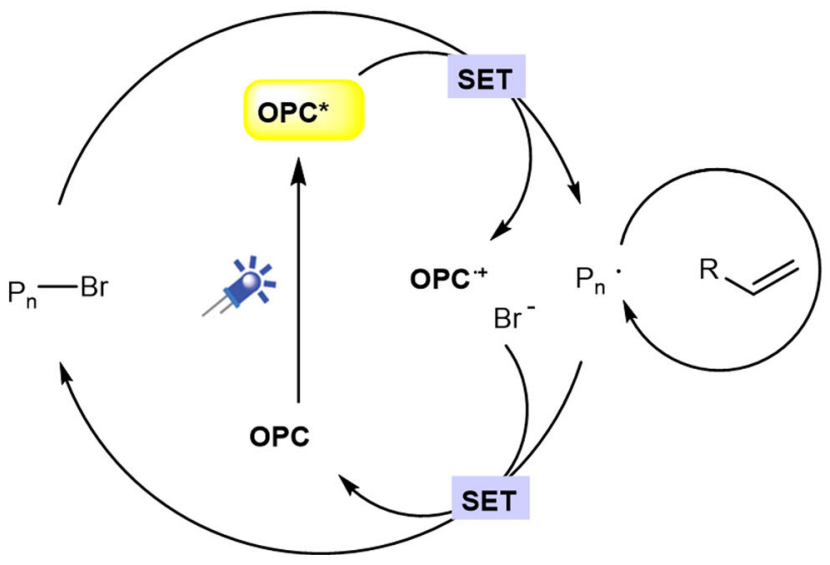

- easy to synthesize

- strong visible light absorption

- high performance

- ppm/sub-ppm loading

\section{O-doped anthanthrene}

(ODA) d Polymerization under sunlight and product color

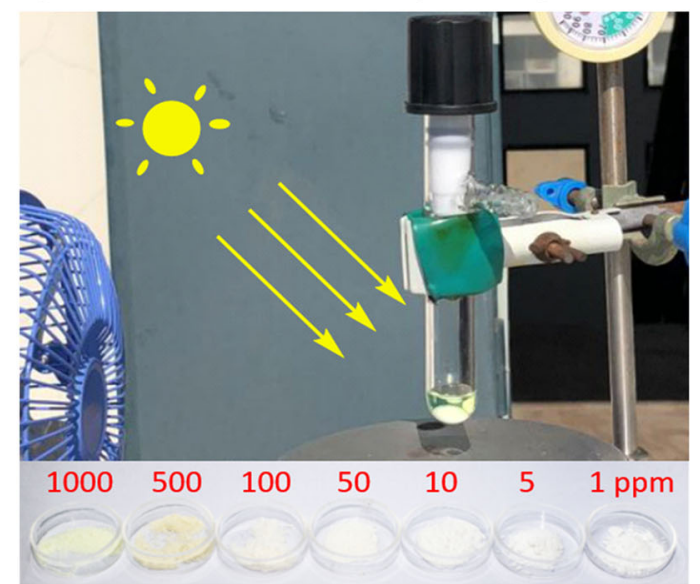

Fig. 1 The development of catalysts for O-ATRP. a Catalyst development via core structure modification. b O-ATRP photocatalyst design based on a heteroatom-doping logic (this work). c Catalytic cycle for a light-mediated O-ATRP. d Polymerization under sunlight and the product color (PMMA). SET single electron transfer, OPC organic photocatalyst, PMMA polymethyl methacrylate. 
a<smiles>Oc1ccc2ccccc2c1-c1c(O)ccc2ccccc12</smiles>

BINOL<smiles>[R]c1cc2ccccc2c(-c2c(O)c([R])cc3ccccc23)c1O</smiles>

BINOL 4a-4d<smiles>[R]c1cc2cccc3c2c2oc4cccc5cc([R])c(oc12)c3c54</smiles>

ODA 5a-d
$R=\quad H \quad 5 a$

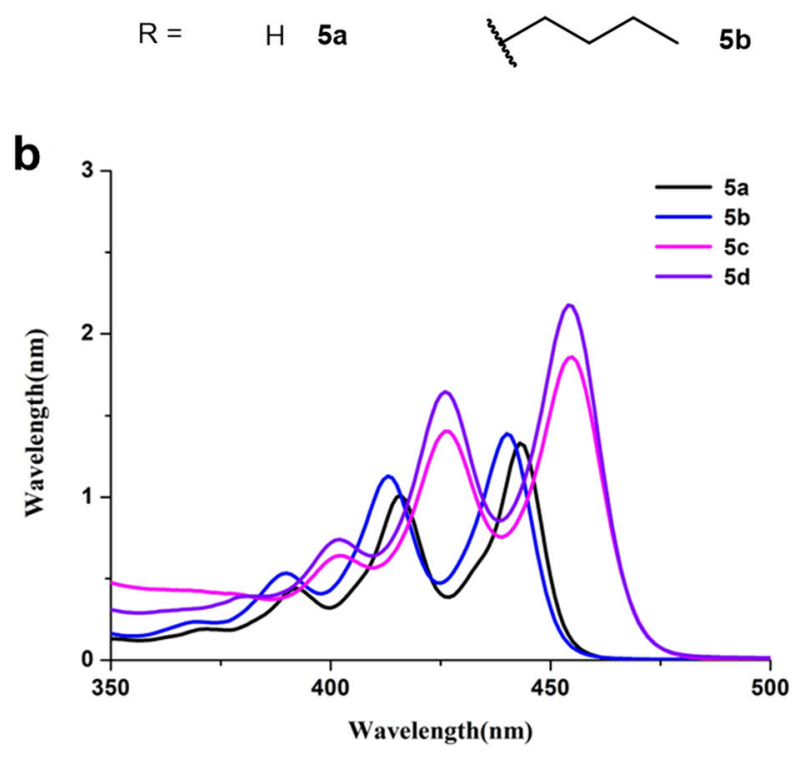

$5 b$

500

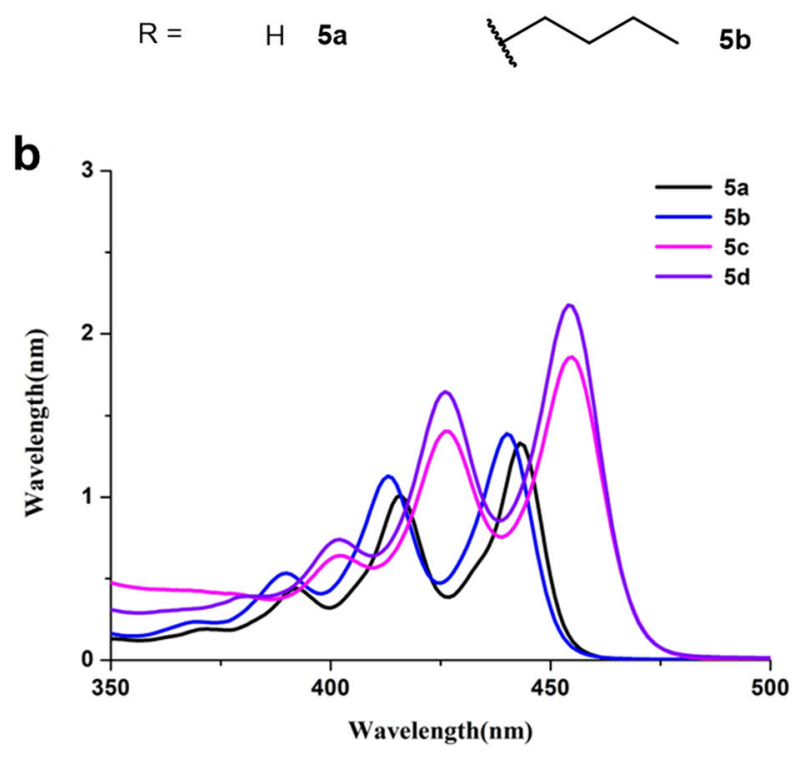

C<smiles>CC(C)(C)c1ccccc1</smiles>
$5 c$
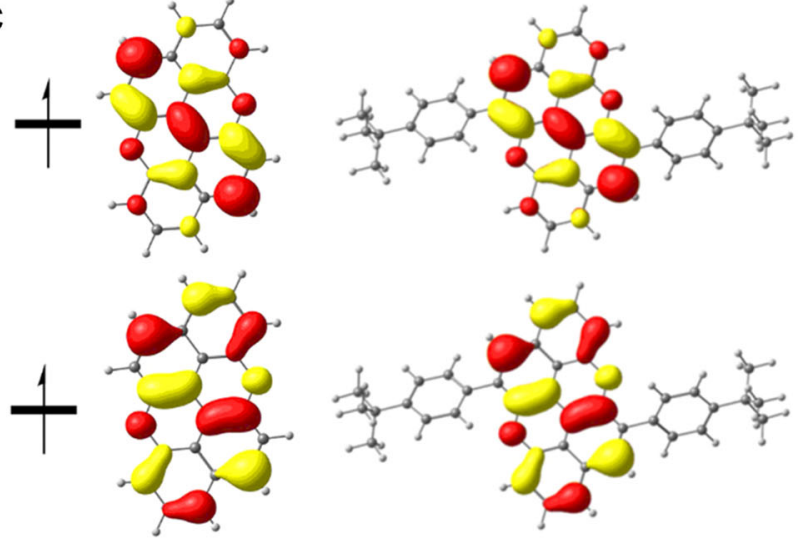

$E^{0}\left(\mathrm{PC}^{\cdot+} /^{3} \mathrm{PC}^{\star}\right) 5 \mathrm{a}(-1.63 \mathrm{~V})$

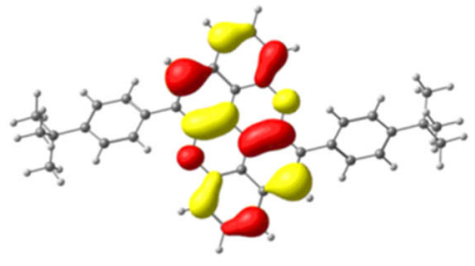

5d $(-1.62 \vee$ vs SCE)<smiles>CC(C)(C)c1ccc(C(C)(C)C)cc1</smiles>

\begin{tabular}{|c|c|c|c|c|}
\hline Photocatalyst (PC) & abs $\lambda_{\max }$ & $\varepsilon_{\lambda \max }$ & $E^{0}(\mathrm{PC} \cdot+/ \mathrm{PC})$ & $E^{0}\left(\mathrm{PC}^{-+} /{ }^{*} \mathrm{PC}\right)$ \\
\hline ODA 5a & $443 \mathrm{~nm}$ & $17450 \mathrm{M}^{-1} \mathrm{~cm}^{-1}$ & $+0.82 \mathrm{~V}$ vs. SCE & $-1.76 \vee v$ vs. SCE \\
\hline ODA 5b & $442 \mathrm{~nm}$ & $18460 \mathrm{M}^{-1} \mathrm{~cm}^{-1}$ & $+0.74 \mathrm{~V}$ vs. SCE & -1.84 V vs. SCE \\
\hline ODA 5c & $454 \mathrm{~nm}$ & $22580 \mathrm{M}^{-1} \mathrm{~cm}^{-1}$ & +0.81 V vs. SCE & -1.82 V vs. SCE \\
\hline ODA 5d & $455 \mathrm{~nm}$ & $23950 \mathrm{M}^{-1} \mathrm{~cm}^{-1}$ & +0.80 V vs. SCE & -1.84 V vs. SCE \\
\hline
\end{tabular}

Fig. 2 Synthesis and characterization of photocatalysts. a Synthesis of oxygen-dopants of anthanthrene 5a-d. b UV-Vis absorption profiles. c SOMO orbitals and triplet reducing power of $\mathbf{5 a}$ and $\mathbf{5 d}$. $\mathbf{d}$ Characterization data of photocatalyst $\mathbf{5 a - 5} \mathbf{d}$ by UV-Vis, fluorescence emission, CV, and calculated redox potentials. SCE saturated calomel electrode, SOMO singly occupied molecular orbital, CV cyclic voltammetry.

could also decrease the cost of commercial production. ${ }^{14,28}$ Therefore, the development of highly effective photocatalysts for O-ATRP has thus become a focus of extensive studies in recent years. $^{20-22,24,28}$ Whereas, many mechanistic aspects in O-ATRP remain unclear so far, and there is still a lack of general guidelines for the catalyst design. ${ }^{22,38}$

Phenothiazine, ${ }^{16}$ dihydrophenazine, ${ }^{25}$ and phenoxazine ${ }^{29}$ are among the most efficient and widely used catalyst frameworks that could achieve a well-controlled O-ATRP polymerization with low dispersity. ${ }^{22}$ To further increase the catalyst efficiency, much effort has been dedicated to the modifications of the catalyst structures such as introducing aryl groups, which could enhance the visible-light absorption, but the red shift of absorption maximum $\left(\lambda_{\max }\right)$ was often quite limited. ${ }^{21,22}$ Interestingly, an analysis on the UV-visible-light absorption of these photocatalysts unveiled a uniformly decreased light absorption profile from its absorption maximum $(<400 \mathrm{~nm})$ to visible light. ${ }^{16,22,25,29}$ Therefore, we questioned whether there is a possibility to find a suitable and tunable O-ATRP catalyst framework with its absorption maximum located in the visible-light region, and a stronger light absorption could probably lower the catalyst loading. The three photocatalysts (1-3) can be recognized as derivatives obtained by modifying the corresponding core chromophoric structures: phenothiazine, dihydrophenazine, and phenoxazine, respectively (Fig. 1a). Recently, we were thinking that heteroatom-doping 39,40 of small polycyclic arenes might be a feasible catalyst design logic for the O-ATRP photocatalyst development (Fig. 1b).

According to the oxidative quenching mechanism (Fig. 1c), organic photoredox catalysts possessing a highly reducing excited state are required to reduce the alkyl bromides via a single electron transfer (SET) to initiate the polymerization. ${ }^{41}$ Besides, redox potential, photophysical property, stability, etc. of the related catalytic species are also critical to establish a fast and effective switching between propagating and dormant states of the macro-initiators, thus achieving a controlled polymerization with narrow dispersities. ${ }^{38,41-43}$ The integration of heteroatoms such as $\mathrm{N}, \mathrm{O}, \mathrm{S}$, etc. into aromatic hydrocarbons could regulate 
the photophysical and photoredox properties of these polycyclic arene catalysts ${ }^{39,41}$, and thus probably lead to an improvement in their catalytic performance on polymerization and suppress undesired catalyst decomposition or catalyst-initiation. ${ }^{17,31,32}$ With this idea in mind, we thus decided to practice this heteroatom-doping strategy on graphene, and narrowed down the parental aromatic (extended $\pi$ ) system to anthanthrene (Fig. 1b, left), which possesses the desired strong absorption in the visible-light region. ${ }^{4}$ Oxygen-doping was chosen for the current research, as: (i) the known high-performance photocatalysts for O-ATRP were developed based on the chargetransfer (CT) principle, ${ }^{24-30}$ and typically contain a triaryl amine part, which is required to impose a twisted donor-acceptor structure to favor the CT process. ${ }^{24-28,45}$ Therefore, the development of a completely new photocatalyst framework lacking this moiety and that could also achieve the same level or even better performance can be of fundamental significance, which, to the best of our knowledge, remains unknown so far; (ii) O-doping can regulate the photophysical and redox properties of anthanthrene, probably leading to a more oxidizing $\mathrm{OPC}^{\bullet+}$ in comparison with the typical amine-containing catalysts 1-3, which may thus afford a better deactivation control. ${ }^{25-28,41}$ Here, we report our efforts toward this goal, and the discovery of oxygendoped anthanthrene (ODA) as an effective organocatalyst framework for O-ATRP, which exhibits strong absorption at the visible-light region $\left(\varepsilon_{450 \mathrm{~nm}}>20,000 \mathrm{M}^{-1} \mathrm{~cm}^{-1}\right)$, and allows for a $\mathrm{ppm} / \mathrm{sub}$-ppm level of catalyst loading only to deliver a metalfree, controlled polymerization under visible light or even sunlight (Fig. 1d).

\section{Results}

Catalyst synthesis and characterization. The ODA can be readily constructed via dual oxidative cyclization ${ }^{46}$ from the commercially available 1,1'-bisnaphthol (BINOL) (Fig. 2a). Further, by virtue of its high modifiability, ${ }^{47}$ ODAs with different substituents can be readily synthesized via a $3,3^{\prime}$-modification of BINOL/oxidative cyclization sequence (see Supplementary Methods). To improve the catalyst solubility, we synthesized the $n$-butyl substituted catalyst $\mathbf{5 b}$, while $\mathbf{5 c}$ and $\mathbf{5 d}$ were prepared to examine the influence of aryl substituents (for synthetic procedures and spectra, see Supplementary Information). As anticipated, 5a did show a strong absorption in the visible-light region (Fig. 2b), with a red shift of the absorption maximum from 437 to $443 \mathrm{~nm}$ (comparing with the parental anthanthrene ${ }^{44}$ ). This absorption profile is in sharp contrast to that of the known photocatalysts such as $\mathbf{1 - 3}$, which possess a smaller conjugation in the core structure and absorption maximums appearing in the ultra-violet region $(<400 \mathrm{~nm})$. Both the absorption maximums $\left(\lambda_{\max }=454\right.$ and $\left.455 \mathrm{~nm}\right)$ of $\mathbf{5 c}$ and $\mathbf{5 d}$ have shown a further red shift (ca. $12 \mathrm{~nm}$ ) as well as enhanced light absorption $\left(\varepsilon_{\max }=22,580\right.$ and 23,950 vs $\left.17,450 \mathrm{M}^{-1} \mathrm{~cm}^{-1}\right)$. In addition, a notable feature of the ODA catalysts substantially different from the known high-performance O-ATRP photocatalysts 24,28 is the lack of a charge-separation in their excited states (Fig. 2c). Based on the fluorescence emission and the cyclic voltammetry (CV) data, we could assess the reducing capability of the excited singlet states $\left(E^{0 *}\left(\mathrm{PC}^{\bullet}+{ }^{1} \mathrm{PC}^{*}\right)\right)$ of these catalysts, ranging from -1.76 to $-1.84 \mathrm{~V}$ vs SCE (saturated calomel electrode) (Fig. 2d). Density functional theory (DFT) was used to estimate the reduction ability of the triplet excited-states $\left(E^{0}\right.$ $\left(\mathrm{PC}^{\bullet}+{ }^{3} \mathrm{PC}^{*}\right)$, which are in the range of -1.58 to $-1.71 \mathrm{~V}$ vs SCE (Fig 2c, for details, see Supplementary Information and Computational details). Although the excited states of ODA 5a-5d are less reductive than that of $N$-phenyl phenothiazine $(1, A r=P h, R=H$, $E^{0 *}=-2.1 \mathrm{~V}$ vs SCE), ${ }^{16}$ all are more negative than $-0.7 \mathrm{~V}$ that is required to reduce ethyl a-bromophenylacetate (EBP, a common initiator, $\left.E^{0}\left(\mathrm{EBP} / \mathrm{EBP}^{\bullet-}\right)=-0.74 \mathrm{~V} \mathrm{SCE}\right) .^{25}$ Notably, the radical cations $\left(\mathrm{PC}^{\bullet+}\right)$ of ODA catalysts are much more oxidizing (up to $+0.82 \mathrm{~V}$ vs SCE), in comparison with the most efficient dihydrophenazine-based photocatalyst $(+0.38 \mathrm{~V}$ vs SCE $) .^{28}$

Initial evaluation of the photocatalysts. We conducted the initial evaluation of these oxygen-doped catalysts in the polymerization of methyl methacrylate (MMA) by using EBP as initiator, dimethylacetamide (DMA) as solvent under the irradiation of purple lightemitting diodes (LEDs, $\lambda_{\max } 400 \mathrm{~nm}$ ). To our delight, 5a could afford a controlled polymerization with a moderate dispersity (Table 1, entry 1). The polymerization can also be conducted with control in other solvents, such as dimethylformamide (DMF, entry 2), dichloromethane (DCM), toluene, tetrahydrofuran, etc. (Supplementary Table 2). DCM gave the lowest dispersity $(Ð=1.25)$ together with a good agreement between the experimental and theoretical $M_{n}$ (entry 3). Remarkably, ODA $\mathbf{5 a}$ is also effective with other initiators such as ethyl-bromopropanoate ( $\mathrm{EBrP})$, ethyl-2bromoisobutanoate $(\mathrm{EBiB})$, diethyl 2-bromomalonate (DBM), and diethyl 2-bromo-2-methylmalonate (DBMM) $(Ð 1.19-1.27$, entries 4-7). 5b-5d with different substituents were then compared under the standard conditions by using EBP as the initiator. Pleasingly, all the three new catalysts are effective for the polymerization (entries

Table 1 Catalyst evaluation in the atom-transfer radical polymerization of MMA.

\begin{tabular}{|c|c|c|c|c|c|c|c|}
\hline Entry & PC & Initiator & Solvent & Conv. (\%) & $M_{n, \text { theo }}(\mathrm{kDa})$ & $M_{n, \text { GPC }}(\mathrm{kDa})$ & $\bigoplus$ \\
\hline 1 & $5 a$ & EBP & DMA & 88.5 & 9.10 & 19.9 & 1.34 \\
\hline 2 & $5 a$ & EBP & DMF & 83.4 & 8.59 & 18.3 & 1.33 \\
\hline 3 & $5 a$ & EBP & $\mathrm{DCM}$ & 73.3 & 7.58 & 12.8 & 1.25 \\
\hline 4 & $5 a$ & $\mathrm{EBrP}$ & DCM & 72.7 & 7.46 & 13.3 & 1.27 \\
\hline 5 & $5 a$ & $E B i B$ & DCM & 78.2 & 8.02 & 14.9 & 1.23 \\
\hline 6 & $5 a$ & DBM & DCM & 80.8 & 8.33 & 13.7 & 1.22 \\
\hline 7 & $5 \mathbf{a}$ & DBMM & DCM & 81.2 & 8.38 & 12.8 & 1.19 \\
\hline 8 & $5 b$ & EBP & DCM & 66.5 & 6.90 & 12.3 & 1.19 \\
\hline 9 & $5 c$ & EBP & DCM & 79.2 & 8.17 & 13.8 & 1.22 \\
\hline 10 & 5d & EBP & DCM & 88.2 & 9.07 & 13.5 & 1.23 \\
\hline 11 & $5 b$ & DBMM & DCM & 69.1 & 7.17 & 13.5 & 1.15 \\
\hline 12 & $5 d$ & DBMM & DCM & 84.8 & 8.75 & 12.0 & 1.12 \\
\hline $13^{a}$ & $5 a$ & EBP & DCM & 82.7 & 8.52 & 15.7 & 1.25 \\
\hline $14^{a}$ & $5 d$ & DBMM & DCM & 71.8 & 7.44 & 10.9 & 1.15 \\
\hline
\end{tabular}

Reaction conditions: $[\mathrm{MMA}]_{0}:[\text { initiator }]_{0}:[\mathbf{P C}]_{0}=100: 1: 0.05$, solvent $(9.4 \mathrm{M}$ of $\mathrm{MMA})$, at room temperature, under the irradiation of purple $\mathrm{LEDs}\left(400 \mathrm{~nm}, 25 \mathrm{~mW} \mathrm{~cm}{ }^{-2}\right), 10 \mathrm{~h}$. Conversions were determined by ${ }^{1} \mathrm{H}$ NMR. $M_{n}$ and $\Theta$ were determined by GPC with polymethyl methacrylate (PMMA) standards. Abbreviations: MMA methyl methacrylate, $P C$ photocatalyst, Conv. conversion, GPC gel permeation chromatography, $D=M_{w} / M_{n}$, EBP ethyl $\alpha$-bromophenylacetate, $E B r P$ ethyl-bromopropanoate, $E B i B$ ethyl-2-bromoisobutanoate, $D B M$ diethyl 2-bromomalonate, $D B M M$ diethyl 2-bromo-2methylmalonate, DMA dimethylacetamide, DMF dimethylformamide, DCM dichloromethane. alrradiated by blue LEDs $\left(460 \mathrm{~nm}, 30 \mathrm{~mW} \mathrm{~cm}^{-2}\right), 8 \mathrm{~h}$. 
a

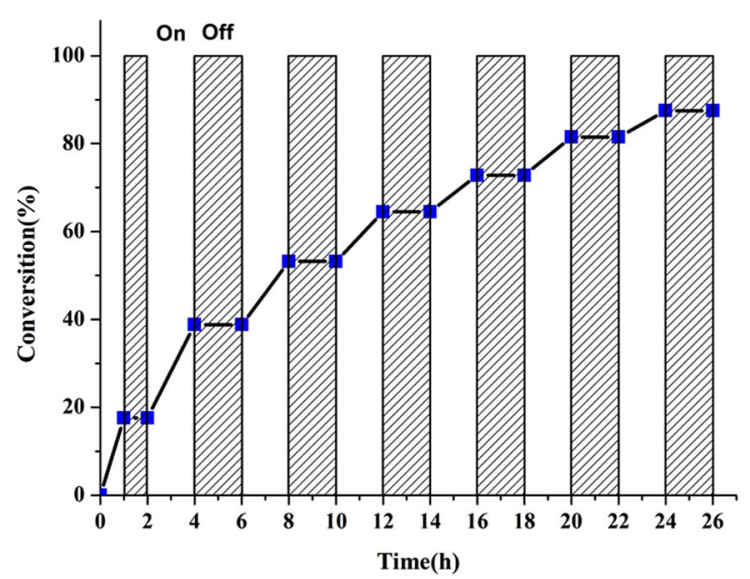

C

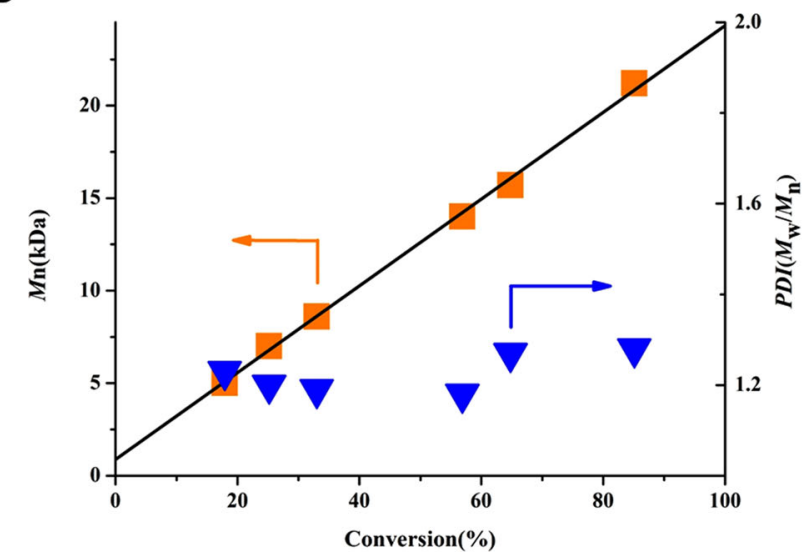

b

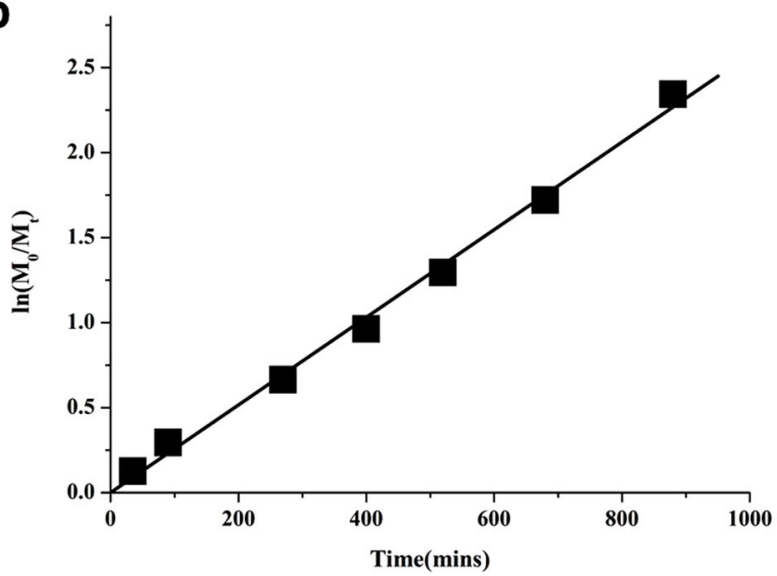

d

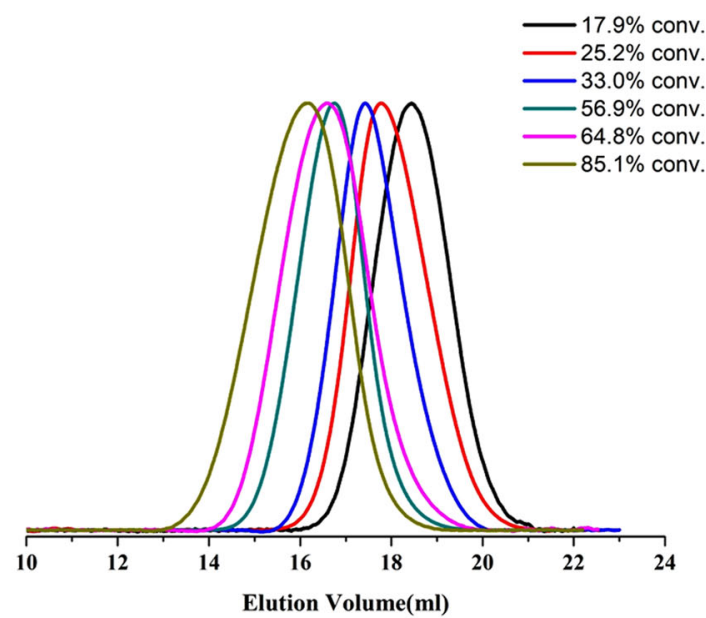

Fig. 3 Temporal control and kinetic study on ODA 5d-catalyzed ATRP of MMA. a Light on-off experiments and the plot of monomer conversion vs time. b Kinetic plot for the metal-free ATRP. c Plot of $M_{n}$ and $\emptyset$ vs monomer conversion for the polymerization of MMA under continuous irradiation. d GPC traces of each polymer depicted in (c) (color coded). All polymerizations were performed at a ratio of $[M M A]_{0}:[D B M M]_{0}:[5 \mathbf{d}]_{0}=200: 1: 0.05$ under purple LED irradiation $\left(400 \mathrm{~nm}, 25 \mathrm{~mW} \mathrm{~cm}^{-2}\right)$.

$8-10)$, and ODA $5 \mathbf{b}$ could achieve a dispersity $(\boxplus)$ lower than 1.20 (entry 8 ). Catalysts $\mathbf{5 b}$ and $\mathbf{5 d}$ were further examined with DBMM (entries 12 \& 13), and a remarkable narrow dispersity $(\bigoplus=1.12$, entry 12) was obtained with 5d. Irradiation with lower energy blue LEDs was also effective (entries 13 \& 14).

Light regulation, kinetics, and block polymer synthesis. A prominent feature of the O-ATRP is that the polymerization can be regulated by light. ${ }^{48,49}$ To examine the temporal control ability of the current system, a light on-off experiment was performed with light on-off cycle repeating for several times until over $90 \%$ conversion was achieved. As depicted in Fig. 3a, the polymerization only preceded in the presence of light irradiation, while no polymerization was observed in dark. Further, light on-off experiments have shown no conversion even over a long dark period up to $12 \mathrm{~h}$. This strict control by light over the whole process suggests an effective activation and deactivation mechanism of the polymerization. The polymerization was then followed by ${ }^{1} \mathrm{H}$ NMR to gain some insights about the polymerization kinetics, which unveiled a first-order kinetics through the course of the reaction (Fig. $3 \mathrm{~b}$ ). The $M_{n, \mathrm{GPC}}$ values were plotted against the monomer conversion, as shown in Fig. 3c, and a linear increase of molecular mass throughout the polymerization process was observed. Notably, the $y$-intercept of the $M_{n}$ vs conversion plot was $870 \mathrm{Da}$, indicating that the control of the polymerization was achieved after the initial addition of $6 \mathrm{MMA}$ (Fig. 3c). ${ }^{25}$ This strict control may benefit from a more efficient deactivation process ${ }^{26,37,45}$ due to the radical cations of ODA photocatalysts possessing a better oxidizing ability, when compared with the dihydrophenazine-derived photocatalysts. ${ }^{25,28}$

Regarding the chain-end fidelity, a polymethyl methacrylate (PMMA) sample obtained via 5d-mediated metal-free ATRP was subjected to MALDI-TOF (matrix-assisted laser desorption/ ionization time-of-flight mass-spectrometer) analysis (Supplementary Fig. 10), which shows a consistence observed molecular weight with the expected values with each peak separated by the mass of one MMA (100 Da), and individual PMMA polymers having the initiating unit at one chain end and a bromine atom at the propagating chain end. An advantage of high chain-end fidelity is it enables the synthesis of block polymers. As shown in Fig. 4, chain extension (PMMA- $b$-PMMA) and block copolymerization products (PMMA- $b$-PBnMA and PMMA- $b$-PBA) can all be prepared with this catalytic system. Notably, the gel permeation chromatography (GPC) traces, all clearly show an obvious shift to higher molecular weight species with little tailing in the homo-polymer regime, giving further support to the high alkyl bromide chain-end fidelity in the PMMA macro-initiators (purified via re-precipitation from methanol) and also a high reinitiation efficiency. Of note, this result is also in consistence with the high initiator efficiency observed in the polymerizations with freshly distilled DBMM (Supplementary Table 8). Moreover, 
a

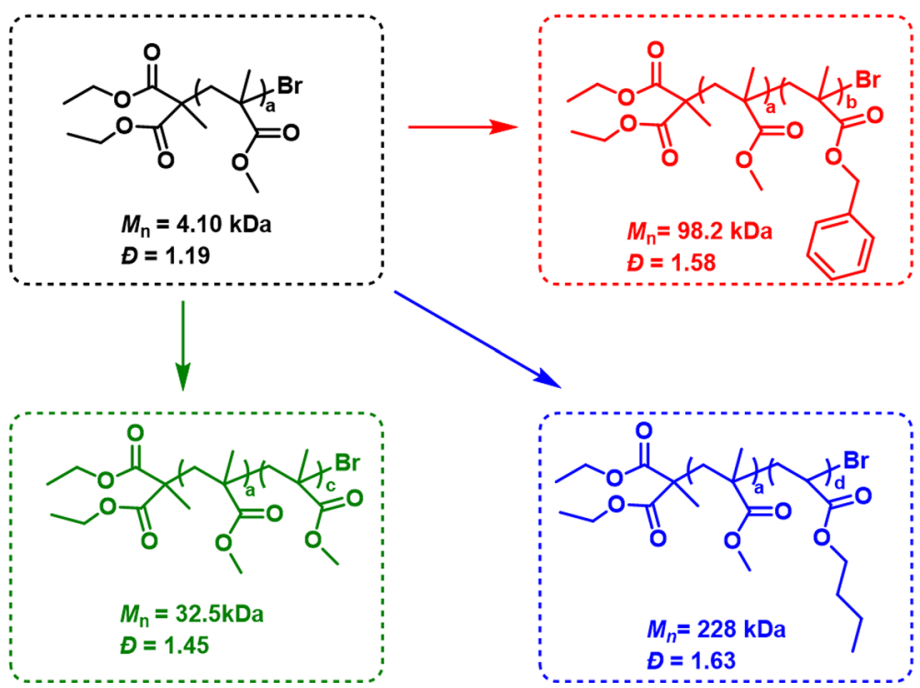

b

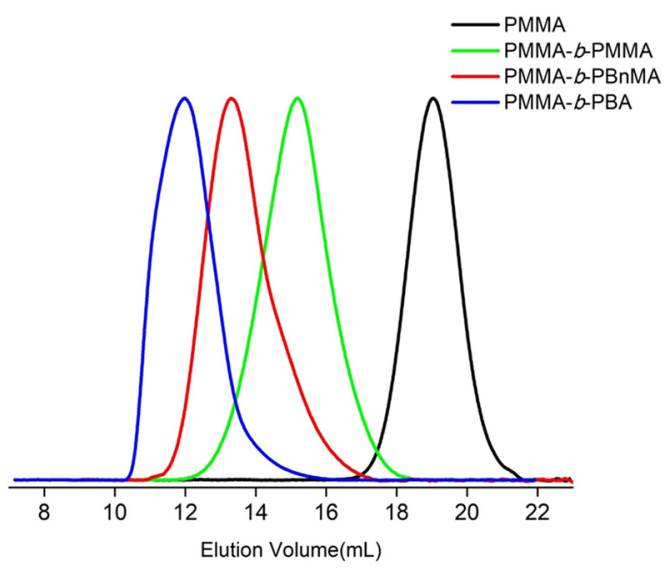

Fig. 4 Block polymer preparation. a Chain-extension from a PMMA macro-initiator (black) to produce block copolymers after a further polymerization with MMA (green), BnMA (red), and BA (blue). b GPC traces of the corresponding polymers depicted in left by using the same color coded. BnMA benzyl methacrylate, $B A$ butyl acrylate.

Table 2 Polymerization with low catalyst loadings.

\begin{tabular}{|c|c|c|c|c|c|c|c|c|c|}
\hline Entry & PC loading (ppm) & Monomer & Initiator & PC & Light source & Time (h) & Conv. (\%) & $M_{n, \mathrm{GPC}}$ & $\bigoplus$ \\
\hline 1 & 100 & MMA & EBP & $5 a$ & Purple LEDs & 10 & 71.4 & 14.3 & 1.19 \\
\hline 2 & 10 & MMA & DBMM & $5 a$ & Blue LEDs & 10 & 88.1 & 14.8 & $1.20(1.09)$ \\
\hline 3 & 10 & MMA & DBMM & $5 d$ & Blue LEDs & 12 & 90.4 & 14.5 & 1.17 (1.08) \\
\hline 4 & 5 & MMA & DBMM & $5 d$ & Blue LEDs & 12 & 83.2 & 14.3 & 1.25 \\
\hline 5 & 0.5 & MMA & DBMM & $5 d$ & Blue LEDs & 14 & 77.4 & 19.2 & $1.34(1.26)$ \\
\hline 6 & 0.1 & MMA & DBMM & $5 d$ & Blue LEDs & 14 & 70.3 & 25.6 & 1.39 \\
\hline 7 & 0.05 & MMA & DBMM & $5 d$ & Blue LEDs & 14 & 62.5 & 30.8 & 1.51 \\
\hline $8^{a}$ & 10 & MMA & DBMM & $5 d$ & Sunlight & 7 & 50.7 & 11.4 & 1.31 \\
\hline $9^{a}$ & 50 & MMA & DBMM & $5 d$ & Sunlight & 7 & 49.2 & 9.40 & 1.22 \\
\hline 10 & 10 & TFEMA & DBMM & $5 d$ & Blue LEDs & 12 & 87.5 & 13.6 & 1.22 \\
\hline 11 & 50 & TFEMA & DBMM & $5 d$ & Blue LEDs & 12 & 81.6 & 11.5 & 1.09 \\
\hline 12 & 50 & BnMA & DBMM & $5 d$ & Blue LEDs & 12 & 93.5 & 11.5 & 1.29 \\
\hline 13 & 10 & BA & DBMM & $5 d$ & Blue LEDs & 7 & 78.2 & 22.3 & 1.49 (1.37) \\
\hline 14 & 50 & BA & DBMM & $5 d$ & Blue LEDs & 7 & 91.6 & 30.8 & $1.41(1.29)$ \\
\hline
\end{tabular}

triblock copolymer synthesis is also viable with this system as demonstrated with the preparation of PMMA- $b$-PBnMA- $b$-PBA (see Supplementary Fig. 13).

Polymerization at low ppm catalyst loadings. The high molarextinction coefficiency ( $\varepsilon_{\max }$ upto $23,950 \mathrm{M}^{-1} \mathrm{~cm}^{-1}$ ) of ODA catalysts at the visible-light region encouraged us to examine their performance at low catalyst loadings. As shown in Tables 1 and 2, decreasing the catalyst loading from 500 to $10 \mathrm{ppm}$, both photocatalysts $\mathbf{5 a}$ and $\mathbf{5 d}$ could maintain their catalytic efficiency, giving a controlled polymerization with low dispersity (Table 2 , entries 1-3). To our delight, in the present system, very narrow dispersity can be achieved with $10 \mathrm{ppm}$ 5d only (entry 3 ). Remarkably, the catalyst loading of $\mathbf{5 d}$ can be further decreased from 10 to $0.1 \mathrm{ppm}$ (entries $3-6$ ), and even to $50 \mathrm{ppb}$ by more than two orders of magnitude (entry 7), which is among the lowest catalyst loadings so far in O-ATRP. ${ }^{28}$ It is worth mentioning that a catalyst loading less than $10 \mathrm{ppm}$ could be very meaningful, which may eliminate the need of the catalyst removal process. Importantly, white polymer products can be obtained at the catalyst loading less than $50 \mathrm{ppm}$, even though the photocatalysts are normally colored compounds (Fig. 1d). The high catalytic performance may benefit from their strong visible-light absorption ( $5 \mathbf{d}, \varepsilon_{455 \mathrm{~nm}}=23,950 \mathrm{M}^{-1} \mathrm{~cm}^{-1}$ ). In fact, the strength of visible-light absorption is approximately one order of magnitude stronger than that of $f a c-\operatorname{Ir}(\mathrm{ppy})_{3}\left(\varepsilon_{458 \mathrm{~nm}}=2450 \mathrm{M}^{-1} \mathrm{~cm}^{-1}\right)$, which is a commonly used organometallic photoredox catalyst. ${ }^{50}$ Remarkably, sunlight is also suitable to drive the polymerization with 10 ppm catalyst only (entries $8 \& 9$ ). To the best of our knowledge, $10 \mathrm{ppm}$ represents the lowest catalyst loading achieved so far in controlled O-ATRP under sunlight. Furthermore, other methacrylate monomers such as 2,2,2-trifluoroethyl methacrylate (TFEMA) and benzyl methacrylate (BnMA) can also be polymerized with low dispersity at 10 or $50 \mathrm{ppm}$ catalyst loading (entries 10-12). Surprisingly, ODA catalysts could also deliver a controlled polymerization with low dispersity in the polymerization of $n$-butyl acrylate (entries $13 \& 14$, also see Supplementary Table 6). It is worth mentioning that acrylate 
monomers proved to be very challenging to achieve a controlled polymerization with low dispersity by O-ATRP methods due to their high polymerization rate. ${ }^{25,28,45}$ To our delight, this control on low dispersity is even better than that with dihydroacridine photocatalysts, which was developed especially for this type of monomers very recently. ${ }^{45}$ Notably, ODA 5d also represents a rare example of organic photocatalysts that could promote the polymerization of both MMA and BA with good controls. ${ }^{28,45}$

\section{Discussion}

In this work, a catalyst design logic based on heteroatom-doping of polycyclic arenes has been successfully introduced into the development of photocatalysts for O-ATRP. ODA has been identified as a catalyst framework with high efficiency, featuring its strong visible-light absorption and excellent performance at very low catalyst loadings (50 ppb to $10 \mathrm{ppm}$ ) in organocatalytic ATRP. This framework also represents a rare example of non- $N$ heterocyclic organocatalysts lacking a CT character that could mediate the ATRP with good control and low dispersity $(\boxplus<1.20)$ at a ppm level of catalyst loading. We anticipate that this class of photoredox catalysts will find further applications in polymer synthesis and other photocatalysis-related fields.

\section{Methods}

Typical procedure for O-ATRP of MMA under light. Typical metal-free organocatalytic ATRP procedures with the molar ratio of $[\mathrm{MMA}]_{0}:$ :[initiator $]_{0}:[$ catalyst $]_{0}=100: 1: 0.05$ were shown as follows. The polymerization was conducted with MMA (1.0 mL, $9.35 \mathrm{mmol}, 100 \mathrm{eq}$.) as the model monomer, DBMM $(18 \mu \mathrm{L}, 93.5$ $\mu \mathrm{mol}, 1.0$ eq.) as the ATRP initiator, organic photocatalyst ( $4.70 \mu \mathrm{mol}, 0.5 \mathrm{eq}$.$) , and$ DCM $(1.0 \mathrm{~mL})$ as the solvent in a Schlenk tube with a PTFE stirring bar. The mixture was deoxygenized by freeze-pump-thaw cycle three times, backfilled argon, and sealed up subsequently. And then the polymerization occurred under purple LED or blue LED or sunlight irradiation at room temperature. After the desired time, the tube was opened under argon and $20.0 \mu \mathrm{L}$ of mixture was syringed out and quenched into $\mathrm{CDCl}_{3}$ containing $250 \mathrm{ppm}$ BHT to determine the monomer conversion by ${ }^{1} \mathrm{H}$ NMR. The reaction mixture was then diluted with $0.5 \mathrm{~mL}$ dichloromethane and dissolved completely, then dripped into $75 \mathrm{~mL}$ methanol and stirred for $2 \mathrm{~h}$. The precipitate was then collected by suction filtration with a Buchner funnel and dried in vacuum oven until a constant weight was achieved, at $30{ }^{\circ} \mathrm{C}$ to give the purified polymers. For details, additional data, and experiments, please see the Supplementary Information (Supplementary Methods, Supplementary Figs. 1-18, Supplementary Tables $1-8$, etc.)

\section{Data availability}

The authors declare that all data supporting the findings of this study are available within the article and Supplementary Information files, and are also available from the corresponding author upon reasonable request.

Received: 7 October 2020; Accepted: 8 December 2020; Published online: 18 January 2021

\section{References}

1. Matyjaszewski, K. Advanced materials by atom transfer radical polymerization. Adv. Mater. 30, 1706441 (2018).

2. Matyjaszewski, K. \& Tsarevsky, N. V. Macromolecular engineering by atom transfer radical polymerization. J. Am. Chem. Soc. 136, 6513-6533 (2014).

3. Braunecker, W. A. \& Matyjaszewski, K. Controlled/living radical polymerization: features, developments, and perspectives. Prog. Polym. Sci. 32, 93-146 (2007).

4. Tsarevsky, N. V. \& Matyjaszewski, K. "Green" atom transfer radical polymerization: from process design to preparation of well-defined environmentally friendly polymeric materials. Chem. Rev. 107, 2270-2299 (2007).

5. Matyjaszewski, K. et al. Diminishing catalyst concentration in atom transfer radical polymerization with reducing agents. Proc. Natl Acad. Sci. USA 103, 15309-15314 (2006).

6. Pintauer, T. \& Matyjaszewski, K. Atom transfer radical addition and polymerization reactions catalyzed by ppm amounts of copper complexes. Chem. Soc. Rev. 37, 1087-1097 (2008).
7. Ding, M., Jiang, X., Zhang, L., Cheng, Z. \& Zhu, X. Recent progress on transition metal catalyst separation and recycling in ATRP. Macromol. Rapid Commun. 36, 1702-1721 (2015).

8. Boyer, C. et al. Copper-mediated living radical polymerization (atom transfer radical polymerization and copper(0) mediated polymerization): from fundamentals to bioapplications. Chem. Rev. 116, 1803-1949 (2016).

9. Corrigan, N., Shamugam, S., Xu, J. \& Boyer, C. Photocatalysis in organic polymer synthesis. Chem. Soc. Rev. 45, 6165-6212 (2016).

10. Zivic, N. et al. Photocatalysts in polymerization reactions. ChemCatChem 8 , 1617-1631 (2016).

11. Ottou, W. N., Sardon, H., Mecerreyes, D., Vignolle, J. \& Taton, D. Update and challenges in organo-mediated polymerization reactions. Prog. Polym. Sci. 56, 64-115 (2016).

12. Pan, X. et al. Photomediated controlled radical polymerization. Prog. Polym. Sci. 62, 73-125 (2016).

13. Dadashi-Silab, S., Doran, S. \& Yagci, Y. Photoinduced electron transfer reactions for macromolecular syntheses. Chem. Rev. 116, 10212-10275 (2016).

14. Shanmugam, S. \& Boyer, C. Organic photocatalysts for cleaner polymer synthesis. Science 352, 1053-1054 (2016).

15. Hu, S., Zhao, J., Zhang, G. \& Schlaad, H. Macromolecular architectures through organocatalysis. Prog. Polym. Sci. 74, 34-77 (2017).

16. Treat, N. J. et al. Metal-free atom transfer radical polymerization. J. Am. Chem. Soc. 136, 16096-16101 (2014).

17. Miyake, G. M. \& Theriot, J. C. Perylene as an organic photocatalyst for the radical polymerization of functionalized vinyl monomers through oxidative quenching with alkyl bromides and visible light. Macromolecules 47, 8255-8261 (2014).

18. Pan, X., Lamson, M., Yan, J. \& Matyjaszewski, K. Photoinduced metal-free atom transfer radical polymerization of acrylonitrile. ACS Macro Lett. 4, 192-196 (2015).

19. Shanmugam, S., Xu, J. \& Boyer, C. Photocontrolled living polymerization systems with reversible deactivations through electron and energy transfer. Macromol. Rapid Commun. 38, 1700143 (2017).

20. Kreutzer, J. \& Yagci, Y. Metal free reversible-deactivation radical polymerizations: advances, challenges, and opportunities. Polymers 10, 35 (2018).

21. Yilmaz, G. \& Yagci, Y. Photoinduced metal-free atom transfer radical polymerizations: state-of-the-art, mechanistic aspects and applications. Polym Chem. 9, 1757-1762 (2018).

22. Discekici, E. H., Anastasaki, A., Read de Alaniz, J. \& Hawker, C. J. Evolution and future directions of metal-free atom transfer radical polymerization. Macromolecules 51, 7421-7434 (2018).

23. Dadashi-Silab, S., Pan, X. \& Matyjaszewski, K. Phenyl benzo[b]phenothiazine as a visible light photoredox catalyst for metal-free atom transfer radical polymerization. Chem. Eur. J. 23, 5972-5977 (2017).

24. Singh, V. K. et al. Highly efficient organic photocatalysts discovered via a computer-aided-design strategy for visible-light-driven atom transfer radical polymerization. Nat. Catal. 1, 794-804 (2018).

25. Teriot, J. C. et al. Organocatalyzed atom transfer radical polymerization driven by visible light. Science 352, 1082-1086 (2016).

26. Lim, C.-H. et al. Intramolecular charge transfer and ion pairing in $\mathrm{N}, \mathrm{N}$-diaryl dihydrophenazine photoredox catalysts for efficient organocatalyzed atom transfer radical polymerization. J. Am. Chem. Soc. 139, 348-355 (2017).

27. Theriot, J. C., Miyake, G. M. \& Boyer, C. A. N,N-Diaryl dihydrophenazines as photoredox catalysts for PET-RAFT and sequential PET-RAFT/O-ATRP. ACS Macro Lett. 7, 662-666 (2018).

28. Cole, J. P., Federico, C. R., Lim, C.-H. \& Miyake, G. M. Photoinduced organocatalyzed atom transfer radical polymerization using low ppm catalyst loading. Macromolecules 52, 747-754 (2019).

29. Pearson, R. M., Lim, C.-H., McCarthy, B. G., Musgrave, C. B. \& Miyake, G. M. Organocatalyzed atom transfer radical polymerization using $\mathrm{N}$-aryl phenoxazines as photoredox catalysts. J. Am. Chem. Soc. 138, 11399-11407 (2016).

30. McCarthy, B. G. et al. Structure-property relationships for tailoring phenoxazines as reducing photoredox catalysts. J. Am. Chem. Soc. 140, 5088-5101 (2018)

31. Allushi, A., Jockusch, S., Yilmaz, G. \& Yagci, Y. Photoinitiated metal-free controlled/living radical polymerization using polynuclear aromatic hydrocarbons. Macromolecules 49, 7785-7792 (2016).

32. Aydogan, C., Yilmaz, G. \& Yagci, Y. Synthesis of hyperbranched polymers by photoinduced metal-free ATRP. Macromolecules 50, 9115-9120 (2017).

33. Huang, Z. et al. Metal-free atom transfer radical polymerization of methyl methacrylate with ppm level of organic photocatalyst. Macromol. Rapid Commun. 38, 1600461 (2017).

34. Kutahya, C. et al. Photoinduced metal-free atom transfer radical polymerization using highly conjugated thienothiophene derivatives. Macromolecules 50, 6903-6910 (2017).

35. Trotta, J. T. \& Fors, B. P. Organic catalysts for photocontrolled polymerizations. Synlett 27, 702-713 (2016). 
36. Corbin, D. A., Lim, C.-H. \& Miyake, G. M. Phenothiazines, dihydrophenazines, and phenoxazines: sustainable alternatives to preciousmetal-based photoredox catalysts. Aldrichim. Acta 52, 7-21 (2019).

37. Dell'Amico, L., Vega-Penaloza, A., Mateos, J., Companyo, X. \& EscuderoCasao, M. A Rational approach to organo-photocatalysis. Novel designs and structure-property-relationships. Angew. Chem. Int. Ed. https://doi.org/ 10.1002/anie.202006416 (2020).

38. Teriot, J. C., McCarthy, B. G., Lim, C.-H. \& Miyake, G. M. Organocatalyzed atom transfer radical polymerization: perspectives on catalyst design and performance. Macromol. Rapid Commun. 38, 1700040 (2017).

39. Duan, J., Chen, S., Jaroniec, M. \& Qiao, S. Z. Heteroatom-doped graphenebased materials for energy-relevant electrocatalytic processes. ACS Catal. 5, 5207-5234 (2015).

40. Liu, J. \& Feng, X. Bottom-up synthesis of nitrogen-doped polycyclic aromatic hydrocarbons. Synlett 31, 211-222 (2020).

41. Pan, X. et al. Mechanism of photoinduced metal-free atom transfer radical polymerization: experimental and computational studies. J. Am. Chem. Soc. 138, 2411-2425 (2016).

42. Chen, M., Zhong, M. \& Johnson, J. A. Light-controlled radical polymerization: mechanisms, methods, and applications. Chem. Rev. 116, 10167-10211 (2016).

43. Koyama, D., Dale, HarveyJ. A. \& Orr-Ewing, A. J. Ultrafast observation of a photoredox reaction mechanism: photoinitiation in organocatalyzed atomtransfer radical polymerization. J. Am. Chem. Soc. 140, 1285-1293 (2018).

44. Shah, B. K., Neckers, D. C., Shi, J., Forsythe, E. W. \& Morton, D. Photophysical properties of anthanthrene-based tunable blue emitters. J. Phys. Chem. A 109, 7677-7681 (2005).

45. Buss, B. L., Lim, C.-H. \& Miyake, G. M. Dimethyl dihydroacridines as photocatalysts in organocatalyzed atom transfer radical polymerization of acrylate monomers. Angew. Chem. Int. Ed. 132, 3235-3243 (2020).

46. Kamei, T., Uryu, M. \& Shimada, T. Cu-catalyzed aerobic oxidative C-H/C-O cyclization of 2,2'-binaphthols: practical synthesis of PXX derivatives. Org. Lett. 19, 2714-2717 (2017).

47. Akiyama, T. Stronger Brønsted acids. Chem. Rev. 107, 5744-5758 (2007).

48. Pan, X., Fantin, M., Yuana, F. \& Matyjaszewski, K. Externally controlled atom transfer radical polymerization. Chem. Soc. Rev. 47, 5457-5490 (2018).

49. Corrigan, N., Yeow, J., Judzewitsch, P., Xu, J. \& Boyer, C. Seeing the light: advancing materials chemistry through photopolymerization. Angew. Chem. Int. Ed. 58, 5170-5189 (2019).

50. Fors, B. P. \& Hawker, C. J. Control of a living radical polymerization of methacrylates by light. Angew. Chem. Int. Ed. 51, 8850-8853 (2012).

\section{Acknowledgements}

We thank Prof. Krzysztof Matyjaszewski (Carnegie Mellon University) and Prof. Junfang Li (Shanghai Institute of Organic Chemistry, CAS) for helpful discussions and suggestions. Dr. Zechun Jiang is highly appreciated for his support with GPC (Wyatt MALS) measurements. Many thanks to Dr. Zhiwei Lin (Xiamen University) for her help in the MALDI-TOF test, and to Prof. Jianjun Sun and Ms. Xingyuan Du (Fuzhou University) for their help in electrochemical measurements. We thank the Recruitment Program of Global Experts, National Natural Science Foundation of China (21602028), Beijing National Laboratory for Molecular Sciences (BNLMS201913), the Hundred-Talent Project of Fujian, and Fuzhou University for the financial support. In memory of my beloved son, David Liao, who remains a lifelong inspiration for my scientific work (S.L.).

\section{Author contributions}

Q.M. conducted the research on the catalyst synthesis, polymerization evaluation, kinetic study, characterization, etc.; J.S. performed the computational study; X.Z., Y. J., and L.J. participated in the catalyst synthesis and polymerization development; S.L. conceived this concept and prepared this manuscript with feedback from Q.M. and J.S

\section{Competing interests}

The authors declare no competing interests.

\section{Additional information}

Supplementary information is available for this paper at https://doi.org/10.1038/s41467 020-20645-8.

Correspondence and requests for materials should be addressed to S.L.

Peer review information Nature Communications thanks Cyrille Boyer, Douglas Henrique Pereira, and the other, anonymous, reviewer(s) for their contribution to the peer review of this work. Peer reviewer reports are available.

Reprints and permission information is available at http://www.nature.com/reprints

Publisher's note Springer Nature remains neutral with regard to jurisdictional claims in published maps and institutional affiliations.

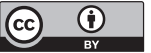

Open Access This article is licensed under a Creative Commons Attribution 4.0 International License, which permits use, sharing, adaptation, distribution and reproduction in any medium or format, as long as you give appropriate credit to the original author(s) and the source, provide a link to the Creative Commons license, and indicate if changes were made. The images or other third party material in this article are included in the article's Creative Commons license, unless indicated otherwise in a credit line to the material. If material is not included in the article's Creative Commons license and your intended use is not permitted by statutory regulation or exceeds the permitted use, you will need to obtain permission directly from the copyright holder. To view a copy of this license, visit http://creativecommons.org/ licenses/by/4.0/.

(C) The Author(s) 2021 